TITLE:

\title{
Risk reduction of distant metastasis in hormone-sensitive postmenopausal breast cancer
}

$\operatorname{AUTHOR}(\mathrm{S}):$

Toi, Masakazu; Yamashiro, Hiroyasu; Tsuji, Wakako

\section{CITATION:}

Toi, Masakazu ... [et al]. Risk reduction of distant metastasis in hormonesensitive postmenopausal breast cancer. Breast Cancer 2009, 16(3):

207-218

ISSUE DATE:

2009-07

URL:

http://hdl.handle.net/2433/85334

\section{RIGHT:}

c 2009 The Japanese Breast Cancer Society.; この論文は出版社版であ りません。引用の際には出版社版をご確認ご利用ください。; This is not the published version. Please cite only the published version. 
Risk reduction of distant metastasis in hormone-sensitive postmenopausal breast cancer Masakazu Toi, Hiroyasu Yamashiro, Wakako Tsuji.

Reprint requests to Dr. MasakazuToi, Department of Surgery and Oncology, Graduate School of Medicine, Kyoto University, 54 Shogoin Kawara-cho, Sakyo-ku, Kyoto, 606-8507, Japan, Tel. +81-75-751-3660; Fax: +81-75-751-3616. E-mail: toi@kuhp.kyoto-u.ac.jp 


\begin{abstract}
Adjuvant endocrine therapy remains the principle strategy to reduce recurrence risk in postmenopausal women with early breast cancer. Studies of the natural history of breast cancer have shown that, while not reaching zero at any time point, the risk of recurrence is highest in the first 5 years following initial diagnosis and treatment. Within this initial 5 years, there is a peak of recurrence at the 2- to 3-year mark. Among the types of breast cancer recurrences observed at this early peak, distant metastasis (DM) predominates over local or contralateral relapse. DM recurrences are most strongly linked to breast cancer-related death, and it has been suggested that adjuvant endocrine therapies that are most effective in minimizing the early peak of DM recurrence may have the most favorable impact on survival in women with early breast cancer. Aromatase inhibitors (AIs) including anastrozole, letrozole, and exemestane have gained popularity in the past few years as alternatives to 5 years of adjuvant tamoxifen, the previous standard of care. However, clinicians have not yet resolved how to best integrate AIs into breast cancer treatment; both upfront therapy (i.e., in lieu of tamoxifen) and a sequential/switch strategy (i.e., after some period of prior tamoxifen) have been proposed. The benefits and drawbacks of these approaches to AI treatment, particularly with respect to reducing early DM recurrences, are reviewed.
\end{abstract}

Keywords: Breast cancer, Distant disease free survival, recurrence, aromatase inhibitor, tamoxifen 


\section{Introduction}

Across the globe, breast cancer remains the most common cancer in women. In the United States, there were an estimated 184,450 new cases of the disease and 40,930 deaths in 2008 [1]. In Europe, breast cancer constituted 28.9\% of all cancers in women in 2006 and was the most commonly diagnosed cancer (both sexes combined), with 429,900 cases [2]. Breast cancer also accounted for nearly 8\% of cancer deaths in Europe, with 131,900 associated deaths in 2006 [2]. Although breast cancer has historically been observed at lower incidences in Japan and other Asian countries [3, 4], this trend appears to have changed in recent years. In Japan, breast cancer incidence has been rapidly increasing [5]. In Japan, breast cancer incidence steadily increased between 1970 and 1995, and cancer registry reports now indicate it to be the leading site of female cancer incidence [6, 7]. Earlier findings of reduced breast cancer incidence in Japanese women may have been related to the regular consumption of isoflavones from soy, as this group of phytoestrogens has been postulated to reduce breast cancer risk through estrogenic and antiestrogenic activities, and a range of other possible mechanisms [4, 8]. Risk factors associated with breast cancer in Japanese women appear to be similar to those identified from studies in the Western world, specifically, age at menarche, age at first delivery, body mass index (in postmenopausal women), and family history [5]. The mortality rate of women with breast cancer in Japan appears to be increasing, and this may be related in part to the increased incidence as well as issues of screening and systemic treatments [9].

The natural history of primary breast cancer in patients receiving adjuvant therapy, stratified by hormone receptor status, is such that in the initial 5 years after surgery, estrogen receptor-positive $(\mathrm{ER}+)$ breast cancer recurrence is lower than ER- breast cancer, and by 10 years, ER+ and ER- breast cancer recurrence is almost equivalent. After 10 years, ER- has lower 
recurrence than $\mathrm{ER}+[10,11]$. Once initially diagnosed and treated, the risk for hormonesensitive breast cancer recurrence remains significant and ongoing. An earlier study suggested a peak of disease recurrence in the first 1-3 years following surgery; however, the recurrence hazard remains well beyond 5 years [11]. Recurrences may develop at local, contralateral, or distant sites, with the latter type typically regarded as the most dangerous, as distant metastases (DM) have been associated with a higher mortality from breast cancer [12]. Recent data suggest that the peak of early recurrences at 2 years post surgery is composed largely of DM, as opposed to locoregional or contralateral recurrence events [13]. Although 5 years of treatment with tamoxifen reduces recurrences and death from breast cancer, and has been used in women with ER + breast cancer for $>2$ decades [10], tamoxifen is declining in favor of the third-generation aromatase inhibitors (AIs) [14]. It has been shown that the AIs anastrozole, letrozole, and exemestane are superior to tamoxifen in terms of disease-free survival (DFS) for postmenopausal women with early-stage ER+ breast cancer, whether used as initial (upfront) adjuvant endocrine therapy (anastrozole or letrozole) or sequential (switch) adjuvant therapy, with the latter strategy employing an AI (exemestane or anastrozole) in women who have already received between 2 and 3 years of tamoxifen $[15,16]$. Both anastrozole $(1 \mathrm{mg} / \mathrm{d})$ and letrozole $(2.5 \mathrm{mg} / \mathrm{d})$ are approved for use in the initial adjuvant setting, while exemestane (25 $\mathrm{mg} / \mathrm{d})$ is approved in the switch setting after 2-3 of tamoxifen. Although AIs are the standard of therapy, questions remain over which strategy (initial/upfront AI use versus switch/sequential use of an AI after tamoxifen) is most appropriate and beneficial in terms of improving DFS, distant DFS (DDFS), and ultimately overall survival (OS). In view of the early peak of disease recurrence at 2-3 years post surgery with tamoxifen, and the predominance of DM events within this peak $[11,13]$, switch strategies may not adequately address the risk of early recurrence. In this review, we discuss the 
impact of early DM recurrence events on the natural history of breast cancer and the results of major AI clinical trials with respect to reducing these events.

\section{Early Relapse Risk}

Although risk factors for breast cancer recurrence such as degree of lymph node involvement and pathological tumor stage have been well defined [17], all patients are at risk for early disease recurrence regardless of their prognostic subgroup. Epidemiological observations show that patients with a higher degree of lymph node involvement have significantly more recurrences than those with fewer nodes involved or node-negative patients $(P<0.00001)$; however, recurrences peak in all groups between years 1 and 5 , and the risk decreases thereafter [11]. Similarly, while patients with larger primary tumors have a significantly higher recurrence rate than those with smaller tumors $(P<0.00001)$, again, recurrences peak in years $1-5$ and decline thereafter [11].

In a more recent PROFARE study of 1588 patients with hormone-dependent, nonmetastatic breast cancer treated with tamoxifen, 633 patients (40.8\%) experienced recurrence or death during follow-up [18]. Of these, 212 recurrences (13.7\%) developed early (within 3 years), and 421 (31.5\%) developed late ( $\geq 3$ years). Of 1550 patients analyzed for OS, 344 (22.2\%) had an recurrence event. Prognostic factors for early and late recurrence were similar to those identified for recurrence overall and included TNM stage T0-T1 versus T2-T4, and $<4$ versus $>4$ involved lymph nodes; however, lower-risk patients also had a substantial risk of relapse [18]. While these findings emphasize the importance of risk factors such as positive lymph nodes, it should be emphasized that recurrence risk is not limited to patients with node-positive disease. Another study, of 9279 individuals who were node-negative in five randomized trials of 
chemotherapy or tamoxifen, found that recurrence risk was evident earlier and was greater for patients who were ER- as compared with ER+ patients; however, the hazard ratio (HR) was more persistent in ER+ patients, and a crossover occurred at about 4 years, resulting in ER+ patients having a greater risk than ER- patients [19]. Similar findings of a crossover in recurrence risk with ER status have been observed in previous studies; however, in both ER- and ER+ disease, the highest peak of recurrences again occurred at about 2 years [11].

The type of recurrence occurring during this early peak is important to consider. Metastasis to distant sites, such as bone and viscera, during this period is associated with a lower likelihood of subsequent remission, and thus, there is good evidence for poorer outcomes for patients with DM as compared with locoregional or contralateral recurrences. In a retrospective cohort study of patients with early breast cancer $(\mathrm{N}=1616)$ with a median follow-up of 44.5 months, there was a recurrence rate of $11.9 \%$ (192 events). Of the recurrences, 58.3\% were DM, 26.1\% were locoregional, and $15.6 \%$ were contralateral. Thus, more than half of the total recurrences in the study were DM events. Compared with the non-recurrence group, patients with DM recurrences had the highest risk of death (HR 13.6; $P<0.001$ ), followed by those with locoregional (HR for death 4.5; $P<0.001$ compared with the non-recurrence group), and contralateral recurrences (HR 3.0, $P=0.01$ ) [12]. Five-year OS probability for patients with distant, locoregional, contralateral recurrence, and no recurrence was $41.3 \%$, 59.3\%, 83.4\%, and 91.7\%, respectively. Median time to all-cause mortality for patients with distant, locoregional, and contralateral recurrences was 41.2 months, 76.9 months, and 89.5 months, respectively. Patients in the DM recurrence group also had a significantly higher risk of breast cancer-related mortality (HR 3.6; $P<0.001$ ) compared with the locoregional group. [12]. Thus, adjuvant 
therapies that reduce the risk of DM may have a significant impact on patient outcomes, as the development of DM directly translates into decreased survival [12].

In another recent analysis of 4245 postmenopausal women with ER+ breast cancer, the annual hazard for recurrence, in addition to the specific type of recurrence, was plotted over the 5-year period following surgery [13]. There was an initial peak of recurrence occurring at 2 years (4.2\%). Importantly, a peak of DM recurrences (3.2\%) was also evident at 2 years, thus, DM constituted most of the overall recurrences at this early time point (Fig 1). By comparison, the annual hazard of locoregional and contralateral recurrence never exceeded $1 \%$, and there was no such peak observed at 2 years [13]. Although patients with low ER positivity, grade 3 pathology, and advanced nodal status are at increased and earlier risk for DM, all patients, including nodenegative patients, are at risk for DM [20]. A mathematical modeling study of patients whose surgery was delayed showed that frequencies of first DM were approximately 1-2\% per month for node-negative T1 patients, 2-4\% for patients with 1-3 nodes involved, and 3-6\% for patients with $>3$ nodes [21]. Other potential predictors of early recurrence include biomarkers such as Ki67 [22] and human epidermal growth factor receptor 2 (HER2) [23]. Tools such as the OncotypeDx test aid in identifying patients at risk for early recurrence [24]. These findings indicate that breast cancer recurrence risk is present at some level across all prognostic groups, the peak of this recurrence occurs at about 2-3 years, and the majority of recurrences are distant events, which are associated with poorer survival compared with locoregional or contralateral events. 


\section{Tamoxifen and Early Recurrence Risk}

Five years of tamoxifen therapy has been the standard of care for patients with HR+ early breast cancer for $>2$ decades, and has been proven across numerous trials to reduce breast cancer recurrences and deaths [10]. In the placebo-controlled National Surgical Adjuvant Breast and Bowel Project (NSABP) B-14 study, 5 years of tamoxifen therapy significantly reduced breast cancer recurrences in women with node-negative, ER+ breast cancer, increasing DFS by 6\% at 4 years $(P<0.00001)$ [25]. An examination of recurrence sites in the NSABP B-14 study demonstrates that the principle impact of tamoxifen was a reduction of local and regional recurrences, as compared with distant recurrences (Fig 2A) [25]. Very similar findings were reported in the Stockholm tamoxifen trial after a median follow-up of 18 years; once again, tamoxifen had a greater impact on local and regional recurrences (relative reduction, 34\%; $P$ $<0.001$ ) compared with its effect on DM (relative reduction, 22\%; $P=0.004$ ) (Fig 2B) [26]. These findings suggest that, despite the significant benefit of tamoxifen therapy in improving DFS and reducing mortality from breast cancer, its greatest impact appears to be in reducing locoregional recurrences which, as noted earlier, constitute only the minority of early recurrences.

Debled and coworkers have recently identified prognostic factors associated with early recurrence in patients receiving tamoxifen for at least 3 years. They found that DM occurred in 38 of 715 patients (5.3\%) within the first 3 years of tamoxifen therapy [27]. Modified ScharfBloom-Richardson (mSBR) grade, axillary lymph node involvement, tumor necrosis, mitotic index, peritumoral vascular emboli, and pathologic tumor size were all identified as significant prognostic factors for early recurrence in a univariate analysis. In multivariate analysis, which excluded grade 1 or lymph node-negative tumors, only mSBR grade was predictive for early recurrence within 3 years of tamoxifen therapy (HR 3.72; $P<0.001$ ). Patients at high risk for 
early recurrence while on tamoxifen can therefore be identified, and such patients may benefit from more effective initial therapies that allow for greater reductions in DM. Of note, one study ( $\mathrm{N}=309$ ) found that even patients considered to be at low risk, such as those with node-negative disease, are at risk for a recurrence event [28].

Finally, the recent issue of the impact of genetic variations in the cytochrome P (CYP) 2D6 gene and use of CYP2D6 inhibitors in relation to tamoxifen has raised much discussion. Researchers found that patients with homozygous variant alleles in the CYP2D6 gene, which is associated with poor metabolism of tamoxifen, had worse recurrence-free time and DFS than did women without this variant allele or who carried only 1 variant allele (i.e. *4/wildtype) [29]. The concurrent use of CYP2D6 inhibitors (e.g. selective serotonin reuptake inhibitors) has also been shown to reduce tamoxifen metabolism and have a negative impact on the outcomes of women treated with tamoxifen $(30,31)$. As a consequence of these findings, in October 2006, the US Food and Drug Administration agreed that the tamoxifen label should be updated to reflect the increased risk for breast cancer in postmenopausal women with ER+ breast cancer who are CYP2D6 poor metabolizers by genotype or drug interaction. Fortunately, the AIs do not use the CYP2D6 pathway for metabolism and have shown superiority over tamoxifen in reducing recurrence risk. Anastrozole and letrozole are now recommended for use as upfront adjuvant AI therapy [32]. DM comprise $>50 \%$ of all breast cancer recurrences in AI trials [33], but a review of data from two upfront AI trials suggest that there may be efficacy differences between the AIs in reducing the risk of DM. 


\section{Upfront Adjuvant AI Therapy to Reduce the Risk of Early DM}

The impact of initial adjuvant therapy with anastrozole versus tamoxifen on breast cancer recurrence was evaluated in the Arimidex, Tamoxifen, Alone or in Combination (ATAC) study. Initial results of the trial at 33.3 months demonstrated significantly better DFS with anastrozole relative to tamoxifen (HR $0.83 ; P=0.013$ ) [34]. As only about $84 \%$ of patients in the ATAC treatment groups were hormone receptor-positive, subsequent analyses have detailed end points in terms of the hormone receptor-positive population as well as the intent-to-treat (ITT) population. At 68 months, the HR for DFS was 0.87 and 0.83 in the ITT and hormone receptorpositive groups, respectively ( $P=0.01$ and 0.005 , respectively). At this time, there was a significant benefit with anastrozole in time to distant recurrence (TTDR) in the ITT population only (HR 0.86; $P=0.04$ ), and the difference in OS was not significant in either study group (ITT, HR 0.97; hormone receptor-positive, HR 0.97; $P=0.7$ ) (Table 1) [35]. The incidence of breast cancer death at 68 months tended to favor anastrozole (ITT, 235 versus 265 events; hormone receptor-positive, 152 versus 172 events) [36]. When considering only the first 2.5 years, there were fewer recurrences overall, as well as fewer locoregional, DM, and contralateral recurrences with anastrozole relative to tamoxifen. However, the greatest effect of anastrozole in terms of risk reduction appeared to be in locoregional and contralateral events [37]. Thus, the ATAC data do not show that initial adjuvant anastrozole prevents the risk of early DM. These findings are important, because the development of DM directly translates into decreased survival. [37].

At 100 months, the longest available median follow-up of the trial, the impact of anastrozole on DFS was maintained in the hormone receptor-positive subgroup (HR 0.85; $P=$ 0.003), and the impact on distant recurrence had reached significance in this population as well (HR 0.84; $P=0.022$ ) [38]. Death after recurrence occurred in 350 and 382 patients in the 
anastrozole and tamoxifen groups, respectively, in the ITT population (HR 0.91; $P=0.2$ ) and in 245 and 269 patients in the hormone receptor-positive population (HR 0.90; $P=0.2$ ). There were no significant effect on OS (ITT population, HR 1.00; $P=0.99$; hormone receptor-positive population, HR 0.97; $P=0.7)$. Efficacy results from ATAC thus demonstrate a significant benefit of initial adjuvant therapy with anastrozole over tamoxifen in terms of DFS, with the greater protection provided to locoregional and contralateral recurrences. A significant benefit in reducing the risk of DM became evident after long-term follow-up (median 100 months) [38].

Tamoxifen Exemestane Adjuvant Multinational (TEAM) study is randomized multinational phase III trial of exemestane compare with tamoxifen in postmenopausal women with endocrine receptor-positive early breast cancer $(\mathrm{N}=9,766)$ [68]. Initial analysis of TEAM study at 2.75 years indicated clinical outcome with exemastane compared with tamoxifen both recurrence (Relapse-free survival, HR 0.85; P=0.05) and DM recurrence (TTDR, HR0.81; $\mathrm{P}<0.03$ ). DFS (HR 0.89; $\mathrm{P}=0.12$ ) and OS did not show a significant difference at this time between the groups (HR 0.86; $P=0.16$ ) (Table 1)

\section{Breast International Group (BIG) 1-98 Trial}

The BIG 1-98 trial is a study designed to assess the efficacy of both initial/upfront and sequential therapy with AIs and tamoxifen in postmenopausal women with hormone receptorpositive breast cancer $(\mathrm{N}=8010)$. Patients in this large cooperative group trial were randomized to 5 years of letrozole, 5 years of tamoxifen, 2 years of letrozole followed by 3 years of tamoxifen, or 2 years of tamoxifen followed by 3 years of letrozole [39]. Results to date have reported only on the effects of letrozole relative to tamoxifen, with the first primary core analysis (PCA) including events in the two monotherapy arms as well as the events occurring in the first 
2 years of the sequential arms, enhancing the statistical power of this comparison. Median follow-up for the PCA was 25.8 months. This analysis reported a significant benefit of letrozole in terms of both recurrences overall (DFS, HR 0.81; $P=0.003$ ) and DM recurrences (TTDR, HR 0.73; $P=0.001$ ); OS did not show a significant difference at this time between the groups (HR 0.86; $P=0.16$ ) (Table 1) [39]. When limiting the analysis to those patients treated in the monotherapy arms with letrozole or tamoxifen, results at a longer follow-up (51 months) were consistent with the primary core analysis. The HR for DFS was $0.82(P=0.007)$, and the HR for TTDR was $0.81(P=0.03)$, while there continued to be no significant benefit in OS (HR 0.91; $P$ $=0.35$ ) [40]. A retrospective analysis of BIG 1-98 has shown that after 2 years of therapy, the majority of early recurrences were DM; patients in the letrozole $(\mathrm{N}=3863)$ and tamoxifen $(\mathrm{N}=$ 3844) groups had, respectively, 12 and 23 local, 11 and 15 contralateral, and 87 and 125 distant recurrences [41]. Although fewer local and contralateral recurrences were observed with letrozole relative to tamoxifen, the prominent benefit was on reducing DM (30\% reduction). This protection with LET is of particular importance at this early time point, especially given the predominance of DM as a first recurrence (74\% of all early recurrences in both treatment groups). Collectively, the efficacy results from BIG 1-98 demonstrate a significant, early benefit of upfront/initial adjuvant therapy with letrozole relative to tamoxifen not only in terms of improving DFS, but also in reducing DM events, which were the dominant early recurrence.

\section{Switch Adjuvant AI Therapy}

A number of trials have investigated the use of AIs following 2-3 years of treatment with tamoxifen. These include the Intergroup Exemestane Study (IES), which compared a switch to exemestane with continued tamoxifen treatment for 5 years total treatment length; and other 
studies, such as the Italian Tamoxifen Arimidex (ITA) trial; the Arimidex-Nolvadex (ARNO) 95 trial; and the Austrian Breast and Colorectal Study Group (ABCSG) 8 trial, which investigated the efficacy of a similar approach using anastrozole $[15,16,42,43]$. Importantly, the ABCSG 8 was the only true sequential trial, as it randomized patients at the time of surgery, as opposed to the other trials, which randomized patients who were alive and disease-free after 2-3 years of prior tamoxifen. The study design of ABCSG 8 thus allows for the inclusion of early events, those occurring in the first 2-3 years following surgery [43]. Full results of the IES and ARNO 95 trial have recently been published, and the anastrozole switch trials have been combined in a meta-analysis.

In the ER+/unknown population of the IES, at 55.7 months, the HR for DFS was 0.75 ( $P$ $=0.0001$ ), corresponding to a 3.5\% absolute improvement in DFS at 5 years [15]. The HR for TTDR was $0.83(P=0.03)$, and after adjustments to the analysis, the HR for OS had reached significance at $0.83(P=0.04)$ (Table 1) [15]. Similarly, in a meta-analysis of the ITA, ARNO 95, and ABCSG 8 studies, which combined results for 2009 patients who switched to anastrozole and 1997 patients who continued on tamoxifen (median 30-month follow up), there were fewer recurrences or deaths (HR 0.59; $P<0.0001)$, a lower number of DM recurrences (HR 0.61; $P=$ 0.0015), and better OS (HR 0.71; $P=0.0377$ ) for patients who switched to anastrozole compared with those who continued on tamoxifen [44]. The significant benefit in DFS (HR 0.66; $P=$ 0.049) and OS (HR 0.53; $P=0.045$ ), as well as a small numerical advantage in DM events with the anastrozole switch (27 versus 33 events), was also observed in the ARNO 95 study when considered on its own [16].

Despite these very encouraging findings of reductions in distant recurrences and significantly improved OS, the caveats of this switch/sequential approach must be emphasized. 
In all cases, these results have considered only those events occurring after the switch, in women who were disease-free following their prior tamoxifen treatment. The most compelling illustration of this can be seen in the results of the ABCSG 8 trial which, as noted earlier, was the only trial to randomize patients at the time of surgery. When events are considered from the point of the switch (i.e., 2 years after surgery), the HR for event-free survival (EFS) with the switch to anastrozole relative to continued tamoxifen is 0.63 and is significant $(P=0.011)$ [43]. However, when events occurring prior to the switch are included (i.e., all events occurring after surgery), the HR for EFS drops to 0.76 and is no longer statistically significant $(P=0.068)$ [43]. It is the only AI trial that has not shown a significant benefit in DFS at 30 months. Patients with recurrences, especially DM recurrences, developing during the early period post surgery when recurrences are at their peak, would thus lose the benefit of AI therapy over tamoxifen. Results of the sequential arms of BIG 1-98, which compare letrozole monotherapy with 2 years of letrozole followed by 3 years of tamoxifen, or 2 years of tamoxifen followed by 3 years of letrozole[67] shows no difference was in 5-year DFS in comparison with sequential therapy arm vs letrozole monotherapy (letrozole followed by tamoxifen;87.6\%, tamoxifen followed by letrozole;86.2\% and letrozole monotherapy;87.9\%), and in OS or TDR in pairwise comparisons at median follow up 71 months. However, a tendency superior to initial tamoxifen in initial letrozole is shown especially in node positive patients who are in relative high risk with early DM (breast cancer recurrence, letrozole followed by tamoxifen;12.5\%, tamoxifen followed by letrozole;14.7\% and letrozole monotherapy;12.4\% ).[67]

\section{Benefits of Reducing Early DM and Potential Differences Between AIs}


Despite the benefits of upfront/initial adjuvant therapy with AIs over tamoxifen in improving DFS and reducing early distant recurrences, a significant improvement in OS has not yet been demonstrated in either the ATAC or BIG 1-98 trials. Earlier trials, however, suggest that early improvements in DFS, and especially DDFS, often precede later significant improvements in OS [33]. For example, in NSABP B-14, tamoxifen improved DDFS over placebo (94\% versus 91\%; $P=0.0005)$ at 48 months' follow up, with no significant improvement in OS (93\% versus 92\%; $P=0.3$ ) [33]. By 120 months, a continued improvement in DDFS was seen with tamoxifen compared to placebo ( $76 \%$ to $67 \%$; $P<0.0001$ ), and OS also significantly improved ( $80 \%$ versus $76 \%$ events; $P=0.02$ ). In two other NSABP chemotherapy trials, B-13 and B-19, similar significant improvements in OS at later follow-up were also preceded by early significant improvement in DDFS events [33]. Early reductions in DM events may therefore be a reliable indicator of forthcoming improvements in long-term survival outcome. Although direct comparisons of the data cannot be made, differences in the magnitude of early(2-3 years after surgery) DM in reductions observed between the AIs studied to date in the initial adjuvant setting, anastrozole (Fig 3A), letrozole (Fig 3B) and exemestane (Fig 3C) are compelling. A direct comparison between anastrozole and letrozole conducted in high-risk, node-positive patients awaits completion in the Femara-Anastrozole Clinical Evaluation (FACE) trial $[45,46]$.

In a randomized crossover study, postmenopausal women with ER+ breast cancer $(\mathrm{N}=$ 54) received either 12 weeks of letrozole followed by 12 weeks of anastrozole or 12 weeks of anastrozole followed by 12 weeks of letrozole, with hormone levels assessed after 12 weeks of each drug [47]. The results showed that following letrozole treatment, fewer patients had estradiol (E2) levels $\geq 3 \mathrm{pmol} / \mathrm{L}$, and the mean E2 and residual E2 levels were lower after 
letrozole than after anastrozole therapy (Table 2). A comparison of letrozole with aminoglutethimide showed an association between estrogen suppression and clinical outcomes [48]. Letrozole provided a greater degree of estrogen suppression [47] and was superior in time to progression, time to treatment failure, and OS [48]. It is possible that the lower estrogen levels observed with letrozole allow for a greater suppression of micrometastatic disease deposits at distant sites, thus providing better protection against the development of early DM.

Another means of assessing the efficacy of the AIs, with respect to DM reduction, is with a number-needed-to-treat (NNT) analysis. Using the initial 33.3-month follow-up data from ATAC [34] and the 25.8-month follow-up data from BIG 1-98 — the most comparable assessments of early recurrences in these trials — Rugo and colleagues estimated that the NNT to prevent one DFS event is comparable for letrozole and anastrozole (63 and 50, respectively) [49]. By comparison, 73 patients would need to be treated with letrozole to prevent one DM event, whereas the NNT for anastrozole was substantially higher-128. In a separate NNT analysis specifically evaluating early recurrence events, which used the ATAC data at 2.5 years [37] and the BIG 1-98 data at 2 years [41], there was a 3-fold difference in NNT for early DM events in favor of letrozole [50]. Differences in trial populations and design may affect such analyses, however these analyses would be useful to assess the potential differences in efficacy [49].

\section{Preventing DM with Initial Adjuvant Endocrine Therapy: Safety Considerations}

Based on results from the major clinical trials of anastrozole and letrozole, the use of AIs over tamoxifen as initial adjuvant therapy for breast cancer to prevent early recurrence, especially early DM, is justified and is recognized as an option by major practice guidelines, 
including those of the St. Gallen consensus and the American Society of Clinical Oncology [32, 51]. Nevertheless, safety must be considered when deciding on the most appropriate adjuvant strategy and for some patients may determine the use of one strategy versus another. Distinctions can be observed between the AIs and tamoxifen in terms of their adverse event profiles. The AIs are more likely to cause well-defined adverse events associated with estrogen deprivation, whereas tamoxifen is associated with potentially serious life-threatening adverse events, such as endometrial cancer and venous thromboembolisms, early on in the course of therapy [52, 53].

Compared with tamoxifen, both anastrozole and letrozole have been associated with significantly more arthralgia and clinical fractures during initial adjuvant treatment [34, 35, 39, 40]. Importantly, musculoskeletal complaints can be managed by analgesics and lifestyle changes, and AI-induced bone loss can be managed with concomitant zoledronic acid [54, 55]. Furthermore, regular bone mineral density monitoring will allow for the early identification of treatment-related bone loss and appropriate intervention in women receiving adjuvant AI therapy [56]. Thus, while bone problems may occur, these adverse events can be managed. The effect of AIs on bone health must be weighed against their superior efficacy over tamoxifen.

All AIs have been associated with some increases in select cardiovascular events and elevated cholesterol levels. In the ATAC trial, there was a higher incidence of ischemic cardiovascular disease in the anastrozole group (4.1\%, versus 3.4\% for tamoxifen; $P=0.1$ ) and significantly more hypercholesterolemia (9\% versus 3.5\%, respectively; $P<0.0001)$ [57]. Unlike ATAC and the other adjuvant AI trials, BIG 1-98 had a more comprehensive collection of safety data (by grades), with a lifelong collection of cardiovascular adverse events. In the BIG 1-98 trial, more patients on letrozole had low-grade hypercholesterolemia (43.6\%, versus $19.2 \%$ for tamoxifen). While grade 3-5 cardiac adverse events were more common with letrozole (96 
versus 57, respectively; $P=0.001$ ), they were relatively rare. Any slight increase in cardiac events with letrozole is outweighed by the superior control of recurrence afforded by this AI compared with tamoxifen $[39,58]$. In the IES, the overall incidence of cardiovascular events was similar between treatment arms (20.8\% for exemestane versus $18.9 \%$ for tamoxifen; $P=$ 0.09) [15]. However, investigators observed small trends towards higher incidences of myocardial infarction $(1.3 \%$ versus $0.8 \%$, respectively; $P=0.08)$, angina $(7.1 \%$ versus $6.5 \% ; P=$ $0.44)$ and ischemic cardiac events $(9.9 \%$ versus $8.6 \% ; P=0.12)$ with exemestane at 55.7 months of follow-up [15].

These events most likely do not represent a true AI-associated adverse event. Rather, they are likely due to the absence of tamoxifen’s apparent beneficial effects on lipids and cardiovascular disease. Of note, letrozole is the only AI to have placebo-controlled cardiovascular data in a large adjuvant trial (MA.17). When letrozole was directly compared with placebo, no detrimental effect of letrozole on lipids was noted, and no increase in cardiovascular adverse events was observed [59]. In addition, the risk of cardiovascular events with AIs is well within the range seen in an age-matched, non-breast cancer population [60].

Other more serious adverse events favor initial adjuvant treatment with AIs over tamoxifen. In particular, venous thromboembolic events (VTE), such as pulmonary embolism and deep vein thrombosis, have been observed at lower frequency with AIs. In the ATAC study, $\geq 1$ VTE was observed in 382 women by the 68-month follow-up, and the odds ratio (OR) for VTE was 0.61 with anastrozole relative to tamoxifen $(P<0.0001)$ [52]. In this study, the risk of VTE was greatest in the initial treatment period but persisted over 5 years. Similarly, in the BIG 1-98 trial, thromboembolic events were reported in 1.5\% of patients on letrozole and 3.5\% of patients on tamoxifen $(P<0.001)$ [39]. Endometrial abnormalities and invasive endometrial 
cancers also appear to occur more frequently in patients receiving tamoxifen relative to those on AIs. Endometrial abnormalities, most commonly polyp formation, were observed at a higher frequency in patients on tamoxifen in the ATAC trial after 6 years of follow up (27\% versus $44 \% ; P=0.17$ ), and the rate of abnormalities was highest in the first treatment year [53]. Moreover, median endometrial thickness increased on tamoxifen and continued until treatment end, whereas it remained unchanged on anastrozole [53]. After 100 months of follow-up, invasive endometrial cancers were seen significantly more with tamoxifen (24 events) than with anastrozole (five events; OR 0.21; $P=0.0004$ ) [38]. Similarly, in BIG 1-98, there was a lower requirement for endometrial biopsy with letrozole relative to tamoxifen (2.3\% versus $9.1 \%$; $P$ $<0.001$ ) and a trend toward less invasive endometrial cancer [39].

There is some emerging evidence for ethnic differences between Asian and Western populations in the adverse-events profiles of the AIs. In a recent assessment of adverse events with anastrozole $(\mathrm{n}=39)$ and tamoxifen $(\mathrm{n}=72)$ in 112 postmenopausal Japanese women with operable breast cancer, there was more weight gain in the anastrozole group (35.8\% versus $12.5 \%$, respectively; $P=0.0036)$, and the average total cholesterol value was significantly lower with tamoxifen (179 versus 214; $P=0.0005$ ), although fatty liver disease developed more frequently with tamoxifen (30.4 versus $6.25 \%$; $P=0.039$ ) [61]. The authors suggest that lipid control and weight maintenance strategies may be appropriate for patients receiving anastrozole.

In another study comparing Japanese women switched from tamoxifen to anastrozole with those who continued on tamoxifen, changes favoring anastrozole were observed for hot flashes and vaginal discharge; however, arthralgia increased in patients on anastrozole [62]. Another study of anastrozole use in Japan demonstrated an incidence of adverse events similar to that seen in the ATAC study [63]. In the MA.17 trial, which investigated the efficacy of extended 
adjuvant letrozole, ethnic minority women experienced fewer hot flashes, fatigue, and arthralgia than white patients [63]. However, the data must be interpreted cautiously, because there was a low percentage of ethnic minority women enrolled in the MA-17 study [64]. Likewise, the MA.27 trial compared menopausal symptoms of AI therapy in white and minority patients and found that minority women receiving adjuvant anastrozole or exemestane have a significantly lower incidence of hot flashes compared with white patients (39.6\% versus $47.4 \%$; $P=0.04$ ) [65]. The potential differences in adverse events with AIs in relation to ethnicity should be explored further.

\section{Conclusions}

The goal of adjuvant endocrine therapy for breast cancer is to minimize the risk for disease recurrence as much as possible in initially treated, surgically resected patients. Although high-risk subgroups of patients, such as those with extensive nodal involvement or high pathological tumor grade, can be identified, all patients with surgically treated breast cancer are at some risk for disease recurrence regardless of their prognostic subgroup. An initial peak of disease recurrence at about 2 years, observed in earlier studies [11], has been confirmed in a more recent analysis of patients with ER+ tumors [13]. The latter study has further delineated this peak of recurrence as being comprised of mainly DM events, which have been associated with poorer survival and death from breast cancer [12]. Preventing DM, especially early in the course of therapy, should translate into an improvement in long-term survival outcome. Consequently, the use of an AI at the earliest opportunity may be the preferred approach to reducing early relapse risk [66]. While the use of AIs following tamoxifen for 2-3 years has improved DDFS, as well as OS. Yet, the initial peak of recurrence at 2 years is not addressed by 
this strategy, nor is the potential breast cancer-associated mortality. Thus, the use of an AI upfront may be justified in most patients [13].

Results from the ATAC and BIG 1-98 trials have clearly shown an improvement in DFS and ATAC, BIG 1-98 and TEAM trials have shown reductions in DM events with upfront/initial adjuvant AI therapy over tamoxifen (Fig 3; Table 1), although no significant improvements in OS have yet been seen. Among these AIs used for upfront therapy, letrozole would appear to be the most effective in preventing early DM recurrences (Fig 3). In BIG 1-98, letrozole demonstrated the greatest reduction in DM (30\%) seen thus far in the initial adjuvant setting in the hormone receptor-positive population and had a pronounced effect on reducing the risk of DM events early on at 2 years (87 letrozole versus 125 tamoxifen; 30\% reduction). A significant impact of anastrozole on distant events in the hormone receptor-positive subgroup was only observed after a longer follow-up (100 months) [38]. The apparent difference in efficacy could in part be related to differences in estrogen suppression, as letrozole is the most potent AI. In addition, a greater reduction in DM was seen with letrozole (30\%) compared with the 7\% reduction seen with anastrozole. Because patient characteristics, definition of distant metastasesfree survival as well as the methods for follow-up are different, it is difficult to compare these results of trials directly. Although these findings suggest that letrozole may be the most appropriate choice for upfront AI therapy, offering the greatest benefit in terms of reducing early distant disease recurrence, and consequently, the potential benefit in improving survival among women with breast cancer. 


\section{References}

1) Jemal A, Siegel R, Ward E, Hao Y, Xu J, Murray T, Thun MJ. Cancer statistics, 2008. CA Cancer J Clin 2008;58:71-96.

2) Ferlay J, Autier P, Boniol M, Heanue M, Colombet M, Boyle P1. Estimates of the cancer incidence and mortality in Europe in 2006. Ann Oncol 2007;18:581-92.

3) Parkin, DM, Whelan SL, Ferlay J, Raymond L, Young J, editors. Cancer incidence in five continents Vol. VII. International Agency for Research on Cancer Scientific Publications No. 143. New York: Oxford University Press; 1999.

4) Yamamoto S, Sobue T, Kobayashi M, Sasaki S, Tsugane S; Japan Public Health CenterBased Prospective Study on Cancer Cardiovascular Diseases Group. Soy, isoflavones, and breast cancer risk in Japan. J Natl Cancer Inst 2003;95:906-13.

5) Ueda K, Tsukuma H, Tanaka H, Ajiki W, Oshima A. Estimation of individualized probabilities of developing breast cancer for Japanese women. Breast Cancer 2003;10:54-62.

6) Minami Y, Tsubono Y, Nishino Y, Ohuchi N, Shibuya D, Hisamichi S. The increase of female breast cancer incidence in Japan: emergence of birth cohort effect. Int J Cancer 2004;108:901-6.

7) Research Group for Population-Based Cancer Registration in Japan. Cancer incidence and incidence rates in Japan in 1995: Estimates based on data from nine population-based cancer registries. Jpn J Clin Oncol 2000;30:318-21.

8) Adlercreutz CH, Goldin BR, Gorbach SL, Höckerstedt KA, Watanabe S, Hämäläinen EK, Markkanen MH, Mäkelä TH, Wähälä KT, Adlercreutz T. Soybean phytoestrogen intake and cancer risk. J Nutr 1995;125(3 Suppl):757S-70S. Erratum in: J Nutr 1995;125:1960. 
9) Ueno M, Kiba T, Nishimura T, Kitano T, Yanagihara K, Yoshikawa K, Ishiguro H, Teramukai S, Fukushima M, Kato H, Inamoto T. Changes in survival during the past two decades for breast cancer at the Kyoto University Hospital. Eur J Surg Oncol 2007;33:696-9.

10) Early Breast Cancer Trialists' Collaborative Group (EBCTCG). Effects of chemotherapy and hormonal therapy for early breast cancer on recurrence and 15-year survival: an overview of the randomised trials. Lancet 2005;365:1687-717.

11) Saphner T, Tormey DC, Gray R. Annual hazard rates of recurrence for breast cancer after primary therapy. J Clin Oncol 1996;14:2738-46.

12) Lamerato L, Havstad S, Gandhi S, Jones D, Chlebowski R. Breast cancer recurrence and related mortality in US patients with early breast cancer. J Clin Oncol 2005;23(16S): 62s. Abstract 738.

13) Doughty JC, Wilson CR, Monypenny IJ, Skene AI, Abram P, Gattuso J, Carpenter R, Angerson WJ, Mansell J. Distant metastasis: the most common type of early recurrence with adjuvant tamoxifen therapy. Breast Cancer Res Treat 2007;106(Suppl 1):S145. Abstract 3057.

14) Aiello EJ, Buist DS, Wagner EH, Tuzzio L, Greene SM, Lamerato LE, Field TS, Herrinton LJ, Haque R, Hart G, Bischoff KJ, Geiger AM. Diffusion of aromatase inhibitors for breast cancer therapy between 1996 and 2003 in the Cancer Research Network. Breast Cancer Res Treat 2008;107:397-403.

15) Coombes RC, Kilburn LS, Snowdon CF, Paridaens R, Coleman RE, Jones SE, Jassem J, Van de Velde CJ, Delozier T, Alvarez I, Del Mastro L, Ortmann O, Diedrich K, Coates AS, Bajetta E, Holmberg SB, Dodwell D, Mickiewicz E, Andersen J, Lønning PE, Cocconi G, Forbes J, Castiglione M, Stuart N, Stewart A, Fallowfield LJ, Bertelli G, Hall E, Bogle RG, 
Carpentieri M, Colajori E, Subar M, Ireland E, Bliss JM; Intergroup Exemestane Study. Survival and safety of exemestane versus tamoxifen after 2-3 years' tamoxifen treatment (Intergroup Exemestane Study): a randomised controlled trial. Lancet 2007;369:559-70. Erratum in: Lancet 2007;369:906.

16) Kaufmann M, Jonat W, Hilfrich J, Eidtmann H, Gademann G, Zuna I, von Minckwitz G.. Improved overall survival in postmenopausal women with early breast cancer after anastrozole initiated after treatment with tamoxifen compared with continued tamoxifen: the ARNO 95 Study. J Clin Oncol 2007; 25:2664-70.

17) Hortobagyi GN, Kau S-W, Buzdar AU, Theriault RL, Booser DJ, Gwyn K, Valero V. What is the prognosis of patients with operable breast cancer (BC) five years after diagnosis? $J$ Clin Oncol 2004; 22(14S): 23. Abstract 585.

18) Azria D, Tubiana-Hulin M, Spielmann M, Coudert B, Monnier A, Serin D, Altweeg T, Namer M, Gligorov J. Prognostic factor for early versus late relapse in non metastatic hormonodependent breast cancers (HBC) treated by tamoxifen. Breast Cancer Res Treat 2006; 100(Suppl 1):S272. Abstract 6047.

19) Dignam JJ, Dukic VM, Anderson SJ, Mamounas EP, Jeong JH, Costantino JP. Timedependent patterns of recurrence after early stage breast cancer: Preliminary observations and methodological issues. J Clin Oncol 2007;25(18S):11a. Abstract 536.

20) Lawrence G, Pritchard MG, Kearins O, Casey M. An analysis of breast cancer recurrences for screen detected and symptomatic breast cancers diagnosed in the West Midlands in 1996 and 1997. Breast Cancer Res Treat 2005; 94(Suppl 1):S211. Abstract 5019. 
21) Thames HD, Buchholz TA, Smith CD. Frequency of first metastatic events in breast cancer: implications for sequencing of systemic and local-regional treatment. J Clin Oncol 1999;17: 2649-58.

22) Viale G, Biobbie-Hurder A; BIG Collaborative Group and International Breast Cancer Study Group (IBCSG). Value of centrally-assessed Ki-67 labeling index as a marker of prognosis and predictor of response to adjuvant endocrine therapy in the BIG 1-98 trial of postmenopausal women with estrogen receptor-positive breast cancer. Breast Cancer Res Treat 2007; 106(Suppl 1):S17. Abstract 64.

23) Rasmussen BB, Regan MM, Lykkesfeldt AE, Dell'Orto P, Del Curto B, Henriksen KL, Mastropasqua MG, Price KN, Méry E, Lacroix-Triki M, Braye S, Altermatt HJ, Gelber RD, Castiglione-Gertsch M, Goldhirsch A, Gusterson BA, Thürlimann B, Coates AS, Viale G; BIG 1-98 Collaborative and International Breast Cancer Study Groups. Adjuvant letrozole versus tamoxifen according to centrally-assessed ERBB2 status for postmenopausal women with endocrine-responsive early breast cancer: supplementary results from the BIG 1-98 randomised trial. Lancet Oncol 2008; 9: 23-8.

24) Habel LA, Achacoso N, Maddala T, Alexander C, Baehner FL, Shak S, Quesenberry C, Gown AM, Goldstein LC. Estrogen receptor and breast cancer survival in a Kaiser Permanente population-based study: comparison of quantitative reverse transcriptase polymerase chain reaction and immunohistochemistry. Breast Cancer Res Treat 2007; 106(Suppl 1):S216. Abstract 5029.

25) Fisher B, Costantino J, Redmond C, Poisson R, Bowman D, Couture J, Dimitrov NV, Wolmark N, Wickerham DL, Fisher ER, et al. A randomized clinical trial evaluating 
tamoxifen in the treatment of patients with node-negative breast cancer who have estrogenreceptor-positive tumors. N Engl J Med 1989; 320: 479-484.

26) Rutqvist LE, Johansson H; Stockholm Breast Cancer Study Group. Long-term follow-up of the randomized Stockholm trial on adjuvant tamoxifen among postmenopausal patients with early stage breast cancer. Acta Oncol 2007; 6: 133-45.

27) Debled M, MacGrogan G, Brouste V, Mathoulin-Pelissier S, Durand M, Mauriac L. Prognostic factors of early distant recurrence in hormone receptor-positive, postmenopausal breast cancer patients receiving adjuvant tamoxifen therapy: results of a retrospective analysis. Cancer 2007;109: 2197-204.

28) Kryj M, Maciejewski B, Withers HR, Taylor JM. Incidence and kinetics of distant metastases in patients with operable breast cancer. Neoplasma 1997;44:3-11.

29) Goetz MP, Rae JM, Suman VJ, Safgren SL, Ames MM, Visscher DW, Reynolds C, Couch FJ, Lingle WL, Flockhart DA. Pharmacogenetics of tamoxifen biotransformation is associated with clinical outcomes of efficacy and hot flashes. J Clin Oncol 2005;23:93129318.

30) Jin Y, Desta Z, Stearns V, et al. CYP2D6 genotype, antidepressant use, and tamoxifen metabolism during adjuvant breast cancer treatment. J Natl Cancer Inst. 2005; 97: 30-39.

31) Goetz MP, Knox SK, Suman VJ, Rae JM, Safgren SL, Ames MM, Visscher DW, Reynolds C, Couch FJ, Lingle WL, Weinshilboum RM, Fritcher EG, Nibbe AM, Desta Z, Nguyen A, Flockhart DA, Perez EA, Ingle JN. The impact of cytochrome P450 2D6 metabolism in women receiving adjuvant tamoxifen. Breast Cancer Res Treat 2007; 101: 113-121.

32) Goldhirsch A, Wood WC, Gelber RD, Coates AS, Thürlimann B, Senn HJ; 10th St. Gallen conference. Progress and promise: highlights of the international expert consensus on the 
primary therapy of early breast cancer 2007. Ann Oncol 2007;18:1133-44. Erratum in: Ann Oncol 2007; 18: 1917.

33) Melisko M, Lin A, Rugo H. Adjuvant therapy for early stage breast cancer (EBC): Distant disease-free survival (DDFS) as a predictor of overall survival (OS). J Clin Oncol 2007; 25(18S): 23s. Abstract 583.

34) Baum M, Buzdar AU, Cuzick J, Forbes J, Houghton JH, Klijn JG, Sahmoud T; ATAC Trialists' Group. Anastrozole alone or in combination with tamoxifen versus tamoxifen alone for adjuvant treatment of postmenopausal women with early breast cancer: first results of the ATAC randomised trial. Lancet 2002; 359: 2131-9. Erratum in: Lancet 2002; 360:1520.

35) Howell A, Cuzick J, Baum M, Buzdar A, Dowsett M, Forbes JF, Hoctin-Boes G, Houghton J, Locker GY, Tobias JS; ATAC Trialists' Group. Results of the ATAC (Arimidex, Tamoxifen, Alone or in Combination) trial after completion of 5 years' adjuvant treatment for breast cancer. Lancet 2005; 365: 60-2.

36) Howell A, on behalf of the ATAC Trialists' Group. ATAC ('Arimidex’, Tamoxifen, Alone or in Combination) completed treatment analysis: Anastrozole demonstrates superior efficacy and tolerability compared with tamoxifen. Breast Cancer Research and Treatment. Supplement 1. Abstract 1, 2004.

37) Houghton J, on behalf of the ATAC Trialists' Group. Initial adjuvant therapy with anastrozole (S) reduced rates of early breast cancer recurrent and adverse events compared with tamoxifen (T) -data reported on behalf of the ATAC ('Arimidex', Tamoxifen, Alone or in Combination) Trialists’ group. Ann Oncol 2006;17 (Suppl 9): ix94. Abstract 243PD. 38) Arimidex, Tamoxifen, Alone or in Combination (ATAC) Trialists' Group, Forbes JF, Cuzick J, Buzdar A, Howell A, Tobias JS, Baum M. Effect of anastrozole and tamoxifen as adjuvant 
treatment for early-stage breast cancer: 100-month analysis of the ATAC trial. Lancet Oncol 2008;9:45-53.

39) Thürlimann B, Keshaviah A, Coates AS, Mouridsen H, Mauriac L, Forbes JF, Paridaens R, Castiglione-Gertsch M, Gelber RD, Rabaglio M, Smith I, Wardley A, Price KN, Goldhirsch A; Breast International Group (BIG) 1-98 Collaborative Group. A comparison of letrozole and tamoxifen in postmenopausal women with early breast cancer. $N$ Engl J Med 2005; 353: 2747-57.

40) Coates AS, Keshaviah A, Thürlimann B, Mouridsen H, Mauriac L, Forbes JF, Paridaens R, Castiglione-Gertsch M, Gelber RD, Colleoni M, Láng I, Del Mastro L, Smith I, Chirgwin J, Nogaret JM, Pienkowski T, Wardley A, Jakobsen EH, Price KN, Goldhirsch A. Five years of letrozole compared with tamoxifen as initial adjuvant therapy for postmenopausal women with endocrine-responsive early breast cancer: update of study BIG 1-98. J Clin Oncol 2007; 25: 486-92.

41) Mauriac L, Keshaviah A, Debled M, Mouridsen H, Forbes JF, Thürlimann B, Paridaens R, Monnier A, Láng I, Wardley A, Nogaret JM, Gelber RD, Castiglione-Gertsch M, Price KN, Coates AS, Smith I, Viale G, Rabaglio M, Zabaznyi N, Goldhirsch A; BIG 1-98 Collaborative Group; International Breast Cancer Study Group. Predictors of early relapse in postmenopausal women with hormone receptor-positive breast cancer in the BIG 1-98 trial. Ann Oncol 2007;18: 859-67.

42) Boccardo F, Rubagotti A, Puntoni M, Guglielmini P, Amoroso D, Fini A, Paladini G, Mesiti M, Romeo D, Rinaldini M, Scali S, Porpiglia M, Benedetto C, Restuccia N, Buzzi F, Franchi R, Massidda B, Distante V, Amadori D, Sismondi P. Switching to anastrozole versus 
continued tamoxifen treatment of early breast cancer: Preliminary results of the Italian Tamoxifen Anastrozole trial. J Clin Oncol 2005; 23: 5138-47.

43) Jakesz R, Gnant M, Greil R, Tausch C, Samonigg H, Kwasny W, Kubista E, Stierer M, Luschin G, Mittlboeck M. The benefits of sequencing adjuvant tamoxifen and anastrozole in postmenopausal women with hormone-responsive early breast cancer: 5 year-analysis of ABCSG Trial 8. Breast Cancer Res Treat 2005; 94(Suppl 1):S10. Abstract 13.

44) Jonat W, Gnant M, Boccardo F, Kaufmann M, Rubagotti A, Zuna I, Greenwood M, Jakesz R. Effectiveness of switching from adjuvant tamoxifen to anastrozole in postmenopausal women with hormone-sensitive early-stage breast cancer: a meta analysis. Lancet Oncol 2006;7: 991-6. Erratum in: Lancet Oncol 2007;8:6.

45) Monnier A. Refining the postmenopausal breast cancer treatment paradigm: the FACE trial. Expert Rev Anticancer Ther 2006; 6:1355-9.

46) Gligorov J, Azria D, Pivot X, Penault-Llorca F, Spielmann M, Namer M. Clinical impact of upfront adjuvant AI therapy on the early risk of recurrence. Eur J Cancer Suppl 2007; 5: 209. Abstract 2.089.

47) Dixon JM, Renshaw L, Young O, Murray J, Macaskill EJ, McHugh M, Folkerd E, Cameron DA, A'Hern RP, Dowsett M. Letrozole suppresses plasma estradiol and estrone sulphate more completely than anastrozole in postmenopausal women with breast cancer. J Clin Oncol 2008; 26:1671-6.

48) Gershanovich M, Chaudri H, Campos D. Letrozole, a new oral aromatase inhibitor: randomised trial comparing $2.5 \mathrm{mg}$ daily, $0.5 \mathrm{mg}$ daily and aminoglutethimide in postmenopausal women with advanced breast cancer. Ann Oncol 1998; 9: 639-45. 
49) Rugo H, Kaura S, Dranitsaris G. The number needed to treat (NNT) as a measure of drug efficacy: The case of aromatase inhibitors (AIs) in post menopausal women with early breast cancer. St. Gallen Conference 2007. Breast 2007;16 (Suppl 1): S61. Abstract P170.

50) Rugo HS, M. Rourke, Dranitsaris G and Kaura S. Letrozole or anastrozole in the prevention of early recurrences in postmenopausal women with early stage breast cancer: using number needed to treat (NNT) to compare benefit. European Breast Cancer Conference, Berlin Germany. 2008, Abstract 236.

51) Winer EP, Hudis C, Burstein HJ, Wolff AC, Pritchard KI, Ingle JN, Chlebowski RT, Gelber R, Edge SB, Gralow J, Cobleigh MA, Mamounas EP, Goldstein LJ, Whelan TJ, Powles TJ, Bryant J, Perkins. American Society of Clinical Oncology technology assessment on the use of aromatase inhibitors as adjuvant therapy for postmenopausal women with hormone receptor-positive breast cancer: Status report 2004. J Clin Oncol 2005; 23: 619-29.

52) Cuzick J, Wale C, on Behalf of the ATAC Trialists' Group. A detailed analysis of the benefits of anastrozole over tamoxifen for venous thromboembolic events (VTEs) after 5 years treatment. Breast Cancer Res Treat 2006;100 (Suppl 1): S24. Abstract 104.

53) Duffy S, on Behalf of the ATAC Trialists' Group. Anastrozole is associated with a lower risk of endometrial abnormalities than tamoxifen: first report of the ATAC trial endometrial subprotocol at 6 years follow-up. Breast Cancer Res Treat 2006;100(Suppl 1):S190. Abstract 4055.

54) Bundred NJ, Campbell ID, Davidson N, DeBoer RH, Eidtmann H, Monnier A, Neven P, von Minckwitz G, Miller JC, Schenk NL, Coleman RE. Effective inhibition of aromatase inhibitor-associated bone loss by zoledronic acid in postmenopausal women with early breast cancer receiving adjuvant letrozole: ZO-FAST Study results. Cancer 2008;112:1001-10. 
55) Brufsky A, Harker WG, Beck JT, Carroll R, Tan-Chiu E, Seidler C, Hohneker J, Lacerna L, Petrone S, Perez EA. et al. Zoledronic acid inhibits adjuvant letrozole-induced bone loss in postmenopausal women with early breast cancer. J Clin Oncol 2007;25:829-36.

56) Chien AJ, Goss PE. Aromatase inhibitors and bone health in women with breast cancer. $J$ Clin Oncol 2006; 24: 5305-12.

57) The Arimidex, Tamoxifen, Alone or in Combination Trialists' Group; Buzdar A, Howell A, Cuzick J, Wale C, Distler W, Hoctin-Boes G, Houghton J, Locker GY, Nabholtz JM. Comprehensive side-effect profile of anastrozole and tamoxifen as adjuvant treatment for early-stage breast cancer: long-term safety analysis of the ATAC trial. Lancet Oncol 2006; 7: 633-43.

58) Mouridsen H, Keshaviah A, Coates AS, Rabaglio M, Castiglione-Gertsch M, Sun Z, Thürlimann B, Mauriac L, Forbes JF, Paridaens R, Gelber RD, Colleoni M, Smith I, Price KN, Goldhirsch A. Cardiovascular adverse events during adjuvant endocrine therapy for early breast cancer using LET or tamoxifen: safety analysis of BIG 1-98 trial. J Clin Oncol. 2007; 25:5715-22.

59) Goss PE, Ingle JN, Martino S, Robert NJ, Muss HB, Piccart MJ, Castiglione M, Tu D, Shepherd LE, Pritchard KI, Livingston RB, Davidson NE, Norton L, Perez EA, Abrams JS, Cameron DA, Palmer MJ, Pater JL. Randomised trial of letrozole following tamoxifen as extended adjuvant therapy in receptor-positive breast cancer: updated findings from NCIC CTG MA.17. J Nat Cancer Inst 2005; 97:1262-71.

60) Sourander L, Rajala T, Raiha I, Makinen J, Erkkola R, Helenius H. Cardiovascular and cancer morbidity and mortality and sudden cardiac death in postmenopausal women on oestrogen replacement therapy (ERT). Lancet 1998; 352:1965-9. 
61) Hori Y, M. Akizuki, R. Nishimura. Comparison of adverse effects on lipid metabolism of Anastrozole with Tamoxifen in adjuvant setting for postmenopausal women with early breast cancer. Eur J Cancer Suppl 2006; 4: 94. Abstract 172.

62) Hozumi Y, Aihara T, Takatsuka Y, Osumi S, Aogi K, Imoto S, Iwata H, Watanabe T, Nakagami K, Ohashi Y. Chronological changes of side effect profile of anastrozole compared with tamoxifen in Japanese women: findings from N-SAS BC03 trial every 3 months after one year of the randomization. Breast Cancer Res Treat 2007;106 (Suppl 1):S145-6. Abstract 3059.

63) Sagara Y, Rai Y. Bone health and anastrozole adverse events in Japan. Breast Cancer Res Treat 2007;106 (Suppl 1):S113. Abstract 2085.

64) Moy B, Tu D, Pater JL, Ingle JN, Shepherd LE, Whelan TJ, Goss PE. Clinical outcomes of ethnic minority women in MA.17: a trial of letrozole after 5 years of tamoxifen in postmenopausal women with early stage breast cancer. Ann Oncol 2006;17: 1637-43.

65) Moy B, Elliott CR, Chapman J-AW, Pater JL, Ding Z, Goss PE. NCIC CTG MA.27: menopausal symptoms of ethnic minority women. Breast Cancer Res Treat 2006;100 (Suppl 1):S144. Abstract 3059.

66) Houghton J, on behalf of the ATAC Trialists' Group. Using anastrozole as initial adjuvant treatment prevents early recurrences and reduces adverse events: Updated data from the ATAC (Arimidex, Tamoxifen, Alone or in Combination) trial. J Clin Oncol 2005; 23 (16S) 24s. Abstract 582.

67) Mouridsen HT, Giobbie-Hurder A, Mauriac L, et al. BIG 1-98: a randomized double-blind phase III study evaluating letrozole and tamoxifen given in sequence as adjuvant endocrine therapy for postmenopausal women with receptor-positive breast cancer. Program and 
abstracts of the 31st Annual San Antonio Breast Cancer Symposium; December 10-14, 2008;

San Antonio, Texas. Abstract 13.

68) Jones SE, Seynaeve C, Hasenburg A, et al. Results of the first planned analysis of the TEAM (tamoxifen exemestane adjuvant multinational) prospective randomized phase III trial in hormone sensitive postmenopausal early breast cancer. Program and abstracts of the 31st Annual San Antonio Breast Cancer Symposium; December 10-14, 2008; San Antonio, Texas. Abstract 15. 


\section{Figure Legends}

Fig. 1 Dominance of distant metastatic recurrences at the 2-year peak of overall recurrences in patients $(\mathrm{N}=4245)$ with estrogen receptor-positive breast cancer.

Shown are the percentages of patients with recurrences overall or distant recurrences at 2 years. No peak was seen for locoregional or contralateral recurrences at 2 years [13].

Fig. 2 Impact of tamoxifen treatment on locoregional and distant recurrences from the National Surgical Adjuvant Breast and Bowel Project B-14 trial and the Stockholm tamoxifen trial. The number of locoregional recurrences in the B-14 trial at 4 years (A) and locoregional recurrences in the Stockholm trial after 18 years' median follow-up (B) are shown, along with the number of distant recurrences in each trial, and the corresponding percent reductions with tamoxifen treatment $[25,26]$

Fig. 3 Early reduction of overall recurrences and distant recurrences in the Arimidex, Tamoxifen, Alone or in Combination (ATAC), Breast International Group (BIG) 1-98 trials and Tamoxifen Exemestane Adjuvant Multinational(TEAM) study.

The total number of recurrences and distant recurrences in the ATAC trial at 2.5 years (A), the BIG 1-98 trial at 2 years (B) and TEAM study at 2.75 years' median follow up is shown, along with the corresponding percent reductions with aromatase inhibitor treatment relative to tamoxifen [34. 41, 68]. 
Table 1. Summary of Results from the Breast International Group (BIG) 1-98, Arimidex, Tamoxifen, Alone or in Combination (ATAC) Trials, Tamoxifen Exemestane Adjuvant Multinational(TEAM) study and the Intergroup Exemestane Study (IES) [35, 38, 40, 67,68,

15 ]

$\begin{array}{lcccccc} & \text { ATAC } & \text { ATAC } & \text { BIG 1-98 } & \text { BIG 1-98 } & \text { TEAM } & \text { IES* } \\ \text { Mediun f/u } & 68 & 100 & 51 & 76 & 31 & 55.7 \\ \mathrm{~N} & 6241 & & 4922 & 4922 & 9766 & 4724 \\ \text { Setting } & \text { initial } & \text { initial } & \text { initial } & \text { initial } & \text { initial } & \text { switch } \\ \text { DFS\# } & & & & & & \\ \quad \text { improve } & \text { Yes } & \text { Yes } & \text { Yes } & \text { Yes } & \text { No } & \text { Yes } \\ \text { HR } & 0.83 & 0.85 & 0.82 & 0.88 & 0.89 & 0.75 \\ \text { p } & 0.005 & 0.003 & 0.007 & 0.03 & 0.12 & 0.0001 \\ \text { Distant recurrence\# } & & & & & & \\ \text { improve } & \text { No } & \text { Yes } & \text { Yes } & \text { Yes } & \text { Yes } & \text { Yes } \\ \text { Event AI/TAM } & 226 / 265 & 0.5 / 357 & 182 / 212 & 257 / 298 & 201 / 244 & 216 / 257 \$ \\ \text { HR for TTDR or DR } & 0.84 & 0.84 & 0.81 & 0.85 & 0.81 & 0.83 \$ \\ \text { p } & 0.06 & 0.022 & 0.03 & 0.05 & 0.03 & 0.03 \$ \\ \text { OS\# } & & & & & & \\ \quad \text { improve } & \text { No } & \text { No } & \text { No } & \text { No } & \text { No } & \text { Yes } \\ \text { HR } & 0.97 & 0.97 & 0.91 & 0.87 & \text { N.A } & 0.83 \\ \text { p } & 0.7 & 0.7 & 0.35 & 0.08 & \text { N.A. } & 0.05\end{array}$

HR = hazard ratio.

TTDR=Time to distant recurrence

$\mathrm{DR}=$ distant recurrence

\#values shown for th hormone receptor-positive population

*values shown in th ER+/unknown group

\$values shown in the ITT analysis 
Table 2. Differential Suppression of Plasma Estradiol (E2) Following 12 Weeks of Treatment with Letrozole or Anastrozole [47]

Letrozole Anastrozole $\quad P$ value

\begin{tabular}{lccc}
\hline Patients with an E2 value of $\geq 3$ & $2 \%$ & $37 \%$ & $<0.001$ \\
pmol/L following treatment & & & \\
Mean E2 level following & $1.56 \mathrm{pmol} / \mathrm{L}$ & $2.71 \mathrm{pmol} / \mathrm{L}$ & $<0.001$ \\
treatment after extrapolation & & & $\mathrm{NR}$ \\
Mean residual E2 level (\% of & $5.9 \%$ & $10.1 \%$ & \\
baseline) & & &
\end{tabular}

NR $=$ not reported. 
Figure 1

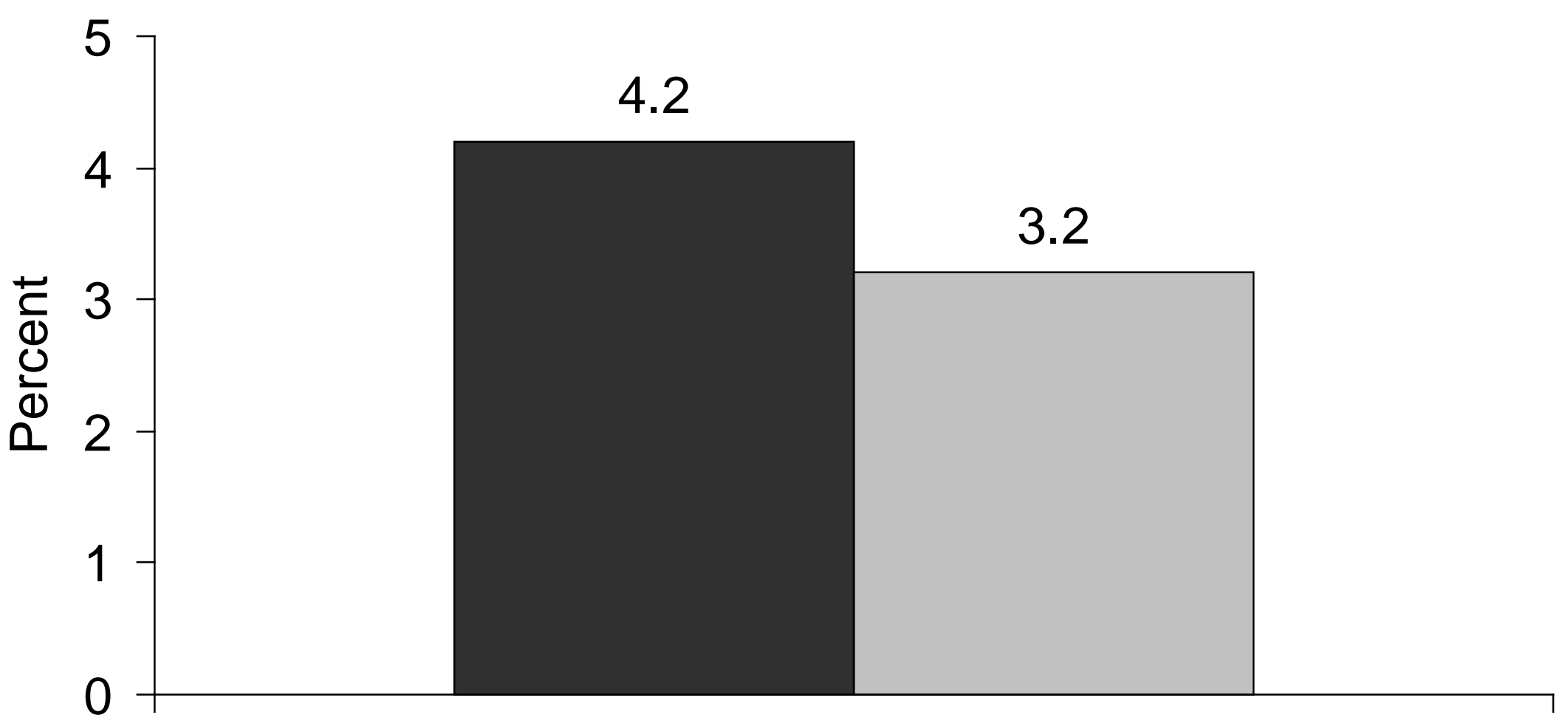

Recurrences at 2 years

$\square$ Overall $\square$ Distant 
Figure 2

A)

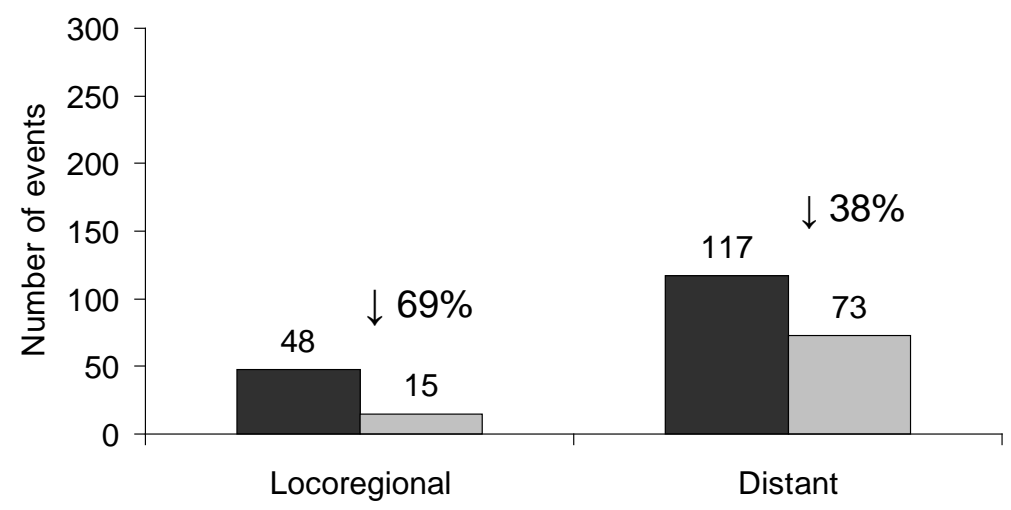

$\square$ Placebo $\square$ Tamoxifen
B)

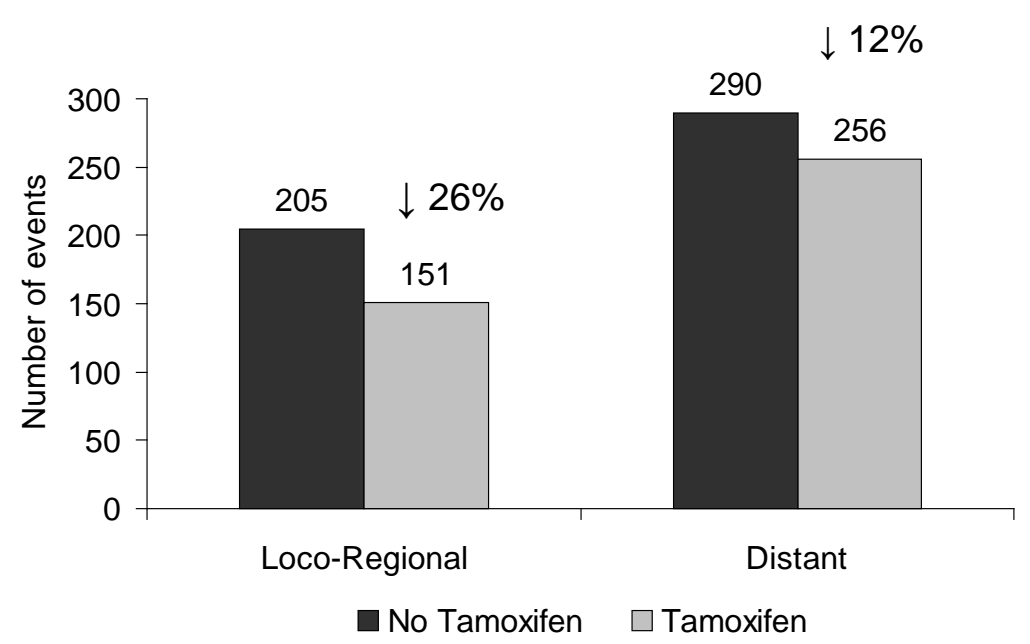


Figure 3

\section{A)}

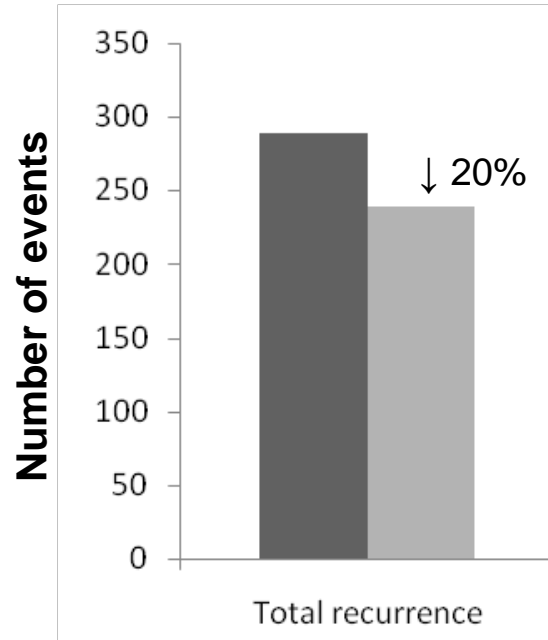

C)
B)

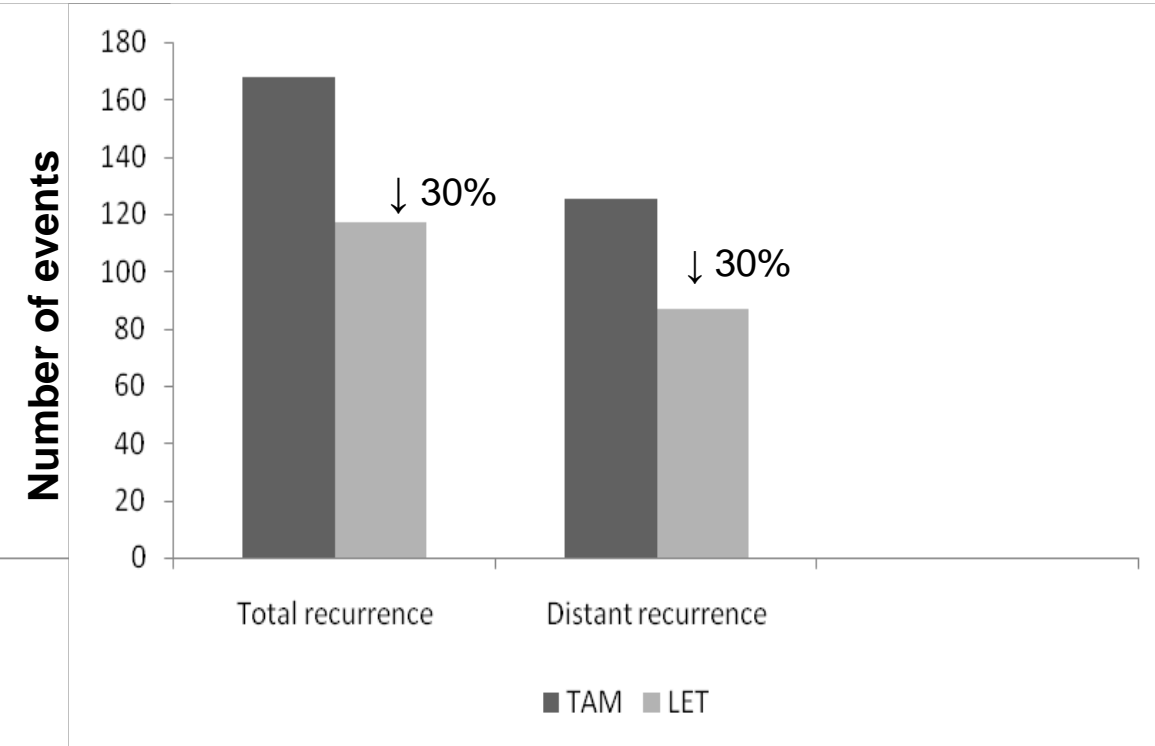

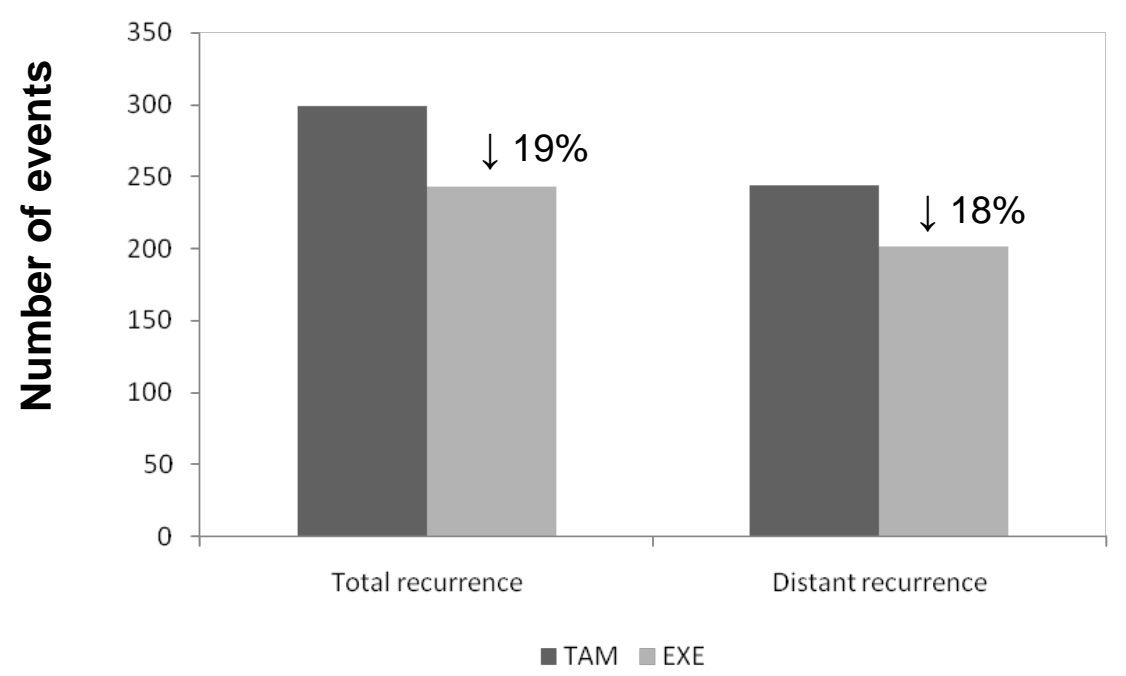

